\title{
Genetic Characterization of Two Human Cases Infected with the Avian Influenza A (H5N6) Viruses - Guangxi Zhuang Autonomous Region, China, 2021
}

\author{
Fuyin $\mathrm{Bi}^{1, \mathrm{k}}$; Lili Jiang, ${ }^{2, \alpha}$; Lihua Huang ${ }^{3}$; Jingguang $\mathrm{Wei}^{3}$; Xiaowen $\mathrm{Pan}^{2} ; \mathrm{Yu} \mathrm{Ju}^{1}$; Jianjun $\mathrm{Mo}^{1}$; \\ Minmei Chen'; Ning Kang'; Yi Tan'; Yonghong Li' ${ }^{1}$; Jing Wang ${ }^{1, * \#}$
}

\section{Summary \\ What is known about this topic? \\ H5N6 has replaced $\mathrm{H} 5 \mathrm{~N} 1$ as a dominant avian influenza virus (AIV) subtype in southern China. The increasing genetic diversity and geographical distribution of $\mathrm{H} 5 \mathrm{~N} 6$ pose a serious threat to the poultry industry and human health. \\ What is added by this report? \\ A total of 2 cases of $\mathrm{H} 5 \mathrm{N6}$ that occurred from February 2021 to July 2021 in Guangxi, China were reported in this study. Phylogenetic analysis of gene was constructed, and some mutations of HA gene, PB2 gene, PA gene, M1 gene, NS1 gene, the receptor- binding site were detected. The evolutionary origins of the internal genes were different. \\ What are the implications for public health practice? \\ As a multi-source reassortant virus, the H5N6 highly pathogenic AIV is continuously evolving. There is an urgent need to strengthen the surveillance of drug- resistant strains and novel variants.}

Since the first human infections with highly pathogenic avian influenza (HPAI) H5N6 virus was detected in Sichuan Province of China in April 2014, a total of 38 human cases and 21 deaths due to H5N6 infection have been reported as of August 6, 2021 in the Western Pacific Region (1). However, the newly emergent HPAI H5N6 virus belonging to the genetic clade 2.3.4.4 of $\mathrm{H} 5$ virus subtypes has possessed the capability for binding human-origin SA- $\alpha, 6 \mathrm{Gal}-$ linked receptor and has demonstrated more transmissibility than $\mathrm{H} 5 \mathrm{~N} 1$ virus in a ferret model (2), suggesting that this subtype virus may be of high public health risk.

Guangxi Zhuang Autonomous Region in southern China has a history of human infection with avian influenza virus (AIV). H7N9 virus emerged here (3) and HPAI H7N9 virus hit this region in 2017, with 27 infections and 14 deaths (4).

\section{INVESTIGATION AND RESULTS}

We reported 2 cases infected with the $\mathrm{H} 5 \mathrm{~N} 6$ virus belonging to genetic clade $2.3 .4 .4 \mathrm{~b}$ and clade $2.3 .4 .4 \mathrm{~h}$ in Guangxi, China in 2021. These 2 cases occurred in two different cities. A case was admitted to the intensive care unit (ICU) due to severe clinical symptoms and was subsequently tested positive for H5N6. The other case was detected from the influenza-like illness (ILI) surveillance system. When a case is found, the local CDC immediately conducts epidemiological and environmental investigations.

On February 16, 2021, a 50-year-old male (Patient A) developed a fever with chest tightness, tightness of breath, headache, cough, sputum, and pneumonia, and was transferred to the Respiratory Department of Hechi People's Hospital for hospitalization on February 21. Patient A had suffered from rheumatoid arthritis for more than 10 years, and he was found to be $\mathrm{H} 5 \mathrm{~N} 6$ influenza virus positive on February 26. He had a history of exposure to infected poultry 9 days before the onset of illness and died on March 2.

On July 6, 2021, a 61-year-old female (patient B) developed a fever with a maximum temperature of $38.5{ }^{\circ} \mathrm{C}$ and was admitted to the Second People's Hospital of Guangxi for treatment on July 9. After 6 days, she was confirmed to be positive for H5N6 by Guangxi CDC. She had a history of chronic gastritis and denied having contact with live poultry.

Viral RNA from the throat swabs of the two patients was extracted using the QIAamp ${ }^{\circledR}$ Viral RNA Mini Kit (Qiagen, Germany), according to the manufacturer's instructions. Specific real-time reverse transcriptase polymerase chain reaction (RT-PCR) assays with specific primer and probe sets for detecting avian influenza A (H5N6). The viral genomes were reversetranscribed and amplified using Easy-Fast FluA whole 
genome amplification one-step kit (Xinlihechuang Technology Co., Ltd.). The sequencing libraries were prepared using the Illumina Nextera ${ }^{\circledR}$ XT Library Prep Kit. The final viral-enriched libraries were sequenced using the Illumina MiSeq platform (Illumina, San Diego, USA). The whole genome sequences of the 2 avian influenza $\mathrm{A}(\mathrm{H} 5 \mathrm{~N} 6)$ strains were assembled and obtained using CLC Genomics Workbench 9.5.2, and the 2 strains were designated A/GX-hechi/01/ 2021(H5N6) (GX01) from Patient $A$ and A/GXguilin/11151/2021(H5N6) (GX11151) from Patient $\mathrm{B}$. The genomes were aligned with the reference genomes downloaded from GISAID (www.gisaid.org) using MAFFT v7.037b (https://mafft.cbrc.jp/ alignment/software/). The genetic and evolutionary analyses were conducted in MEGA 7.0.14 (https://www. megasoftware.net/).

Through sequencing and splicing, 8 gene fragments of the virus were successfully extracted. Some mutations related to viral replication, receptor-binding, mammalian virulence-related markers and drugresistance related markers were detected. The PB2 and MP genes of GX01 virus showed high homology with H9N2 viruses, and the following genes showed high homology with $\mathrm{H} 5 \mathrm{~N} 6$ viruses. The HA and NP genes of GX11151 virus showed high homology with $\mathrm{H} 5 \mathrm{~N} 8$ and $\mathrm{H} 9 \mathrm{~N} 2$ viruses, respectively, and the following genes showed high homology with $\mathrm{H} 5 \mathrm{~N} 6$ viruses (Table 1).
Phylogenetic analysis of HA gene was constructed according to the World Health Organization (WHO) reference sequence. Their nucleotide sequence showed a similarity of $90.7 \%$ between each other. The HA gene of GX01 falls into clade 2.3.4.4h, while GX11151falls into clade2.3.4.4b (Figure 1).

The HA cleavage site of two viruses possessed a multiple basic amino acids motif, indicating potentially high pathogenicity in chickens. The receptor-binding site at the 222-224 motif was QGG of GX01 virus and QRG of GX11151 virus, respectively, suggesting that these viruses preferred binding to avian-like receptors ( $\alpha$ 2,3 SA) (5). However, D94N (6), S133A (7), and T156A (8) mutations in GX01 HA gene, S133A, D155N (8), T156A, and T188I (7) mutations in the GX11151 HA gene increased virus binding to human-like receptors $(\alpha 2-6 \quad S A)$. GX01 virus exhibited 8 potential glycosylation sites at $27,39,70$, 140, 180, 301, 498, and 557 (H5 numbering). GX11151 virus exhibited seven potential glycosylation sites at 27, 39, 180, 209, 301, 498, and 557 (Table 2).

A263T mutation in HA gene was detected in both strains, suggesting that the virulence was enhanced. However, there was no mutation associated with resistance to NA inhibitors in the NA gene of the two strains. K389R, V598T/I mutations of PB2 gene, and N409S mutation of PA gene, which could increase virus replicative ability in mammals, were observed in both strains. Some mutations increasing virulence in

TABLE 1. Similarity analysis of H5N6 virus sequences from the two cases in Guangxi zhuang autonomous region, China, 2021.

\begin{tabular}{|c|c|c|c|c|c|}
\hline Virus & Segment & Length (bp) & Strain with the highest similarity & GISAD ID & Similarity (\%) \\
\hline \multirow{8}{*}{ GX01 } & PB2 & 2348 & A/goose/Fujian/3.15_FZHX0011-O/2018 (H9N2) & EPI1816470 & 92.21 \\
\hline & PB1 & 2341 & A/Guangxi/31906/2018 (H5N6) & EPI1352803 & 100.00 \\
\hline & PA & 2229 & A/chicken/Miyazaki/2-4C/2017 (H5N6) & EPI1891595 & 96.55 \\
\hline & $\mathrm{HA}$ & 1773 & A/chicken/Anhui/8.28_YHZGS017-O/2018 (H5N6) & EPI1825343 & 97.68 \\
\hline & NP & 1565 & A/Guangxi/31906/2018 (A/H5N6) & EPI1352798 & 98.98 \\
\hline & NA & 1431 & A/Env/Guangdong/Qingyuan/C18285099/2018 (H5N6) & EPI1366600 & 98.25 \\
\hline & MP & 1027 & A/chicken/Shanxi/06.28_TGRL001-O/2018 (H9N2) & EPI1833450 & 98.64 \\
\hline & NS & 875 & A/Env/Guangdong/Dongguan/C172863577/2017 (H5N6) & EPI1366948 & 98.86 \\
\hline \multirow{8}{*}{ GX11151 } & PB2 & 2342 & A/Env/Guangdong/zhanjiang/C17277335/2017 (H5N6) & EPI1366759 & 96.63 \\
\hline & PB1 & 2344 & A/Env/Guangdong/zhanjiang/C18277136/2018 (H5N6) & EPI1366684 & 97.78 \\
\hline & PA & 2233 & A/chicken/Miyazaki/2-4C/2017 (H5N6) & EPI891595 & 97.08 \\
\hline & $\mathrm{HA}$ & 1775 & A/chicken/Omsk/0112/2020 (H5N8) & EPI1813345 & 99.44 \\
\hline & NP & 1565 & A/duck/Hunan/5.29_YYGK90P3-OC/2018 (H9N2) & EPI1835016 & 98.72 \\
\hline & NA & 1433 & A/Env/Guangdong/Qingyuan/C18285099/2018 (H5N6) & EPI1366600 & 97.77 \\
\hline & MP & 1027 & A/Sichuan/06681/2021 (A/H5N6) & EPI1883262 & 99.51 \\
\hline & NS & 875 & A/Env/Guangdong/Huizhou/C17280804/2017 (A/H5N6) & EPI1366935 & 98.86 \\
\hline
\end{tabular}




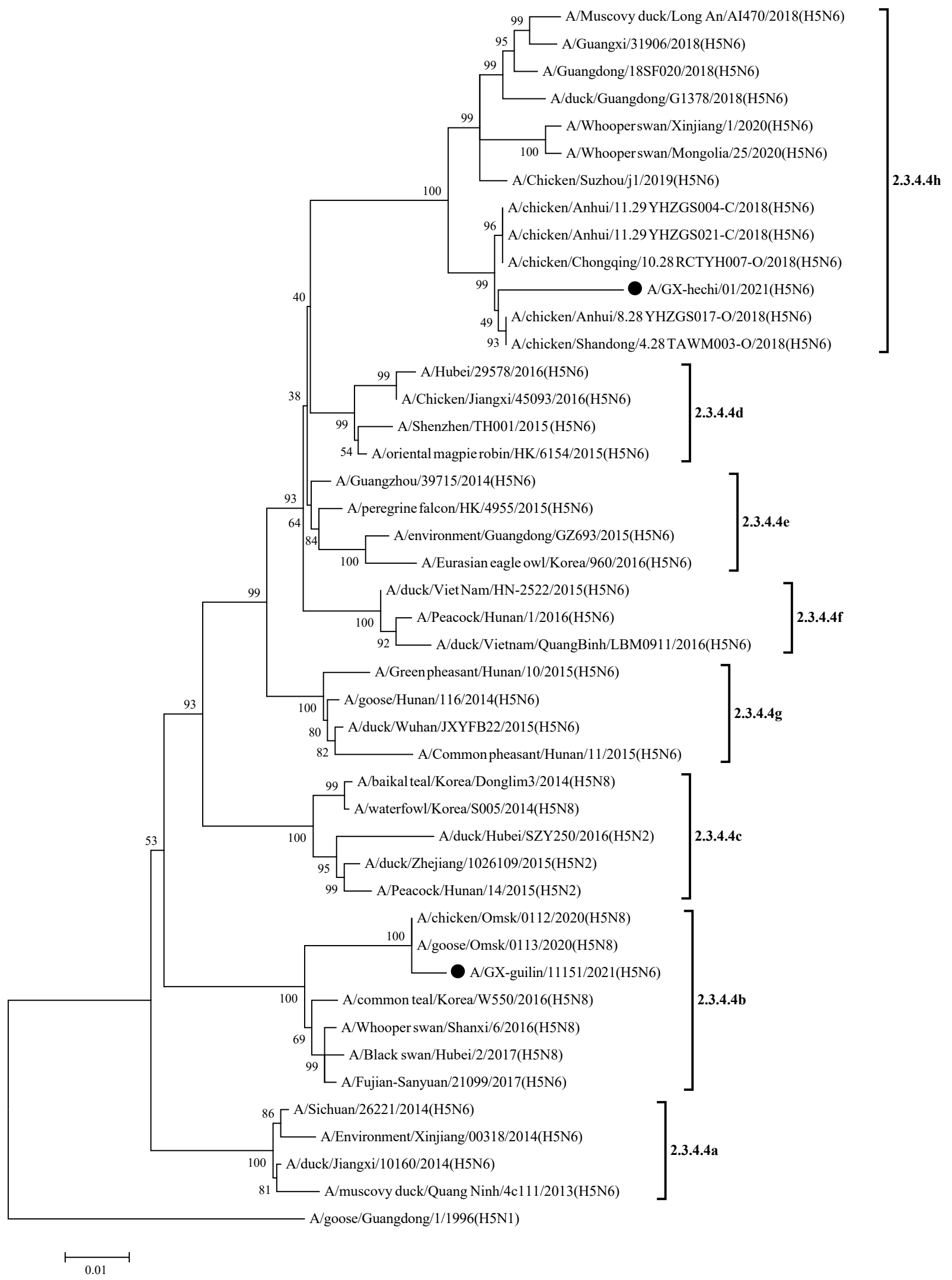

FIGURE 1. Phylogenetic relationships of A (H5) clade 2.3.4.4 HA genes using the maximum likelihood method with 1,000 bootstrap.

Note: The two Guangxi strains were indicated by black dots. 
mice were detected in our strains, such as $\mathrm{N} 30 \mathrm{D}$, T139A, and T215A of M1 gene and P42S and 80-84 deletion of NS1 gene. The M2 gene of GX01 had the mutations of D21G and S31N, suggesting that the strain was resistant to amantadine, but GX11151 was not observed (Table 2).

\section{DISCUSSION}

The previous study showed H5N6 has replaced $\mathrm{H} 5 \mathrm{~N} 1$ as one of the dominant AV subtypes in southern China (9). The avian influenza A (H5N6) virus continues to threaten human life and health.

TABLE 2. Molecular features of the genes of H5N6 viruses isolated from humans.

\begin{tabular}{|c|c|c|c|c|c|c|c|}
\hline Gene & GX01 & GX11151 & SC26221 & GX31906 & GZ39715 & HB29578 & Phenotypic characteristics \\
\hline \multicolumn{8}{|l|}{ HA (H5 no.) } \\
\hline D94N & $\mathrm{N}$ & $\mathrm{S}$ & $\mathrm{N}$ & $\mathrm{N}$ & $\mathrm{N}$ & $\mathrm{N}$ & Increased virus binding to $\alpha 2-6 \mathrm{SA}$ \\
\hline S133A & A & A & $A$ & A & A & $A$ & Increased pseudovirus binding to a $2-6 \mathrm{SA}$ \\
\hline D155N & $\mathrm{D}$ & $\mathrm{N}$ & $\mathrm{D}$ & $\mathrm{D}$ & $\mathrm{D}$ & $\mathrm{D}$ & \multirow{2}{*}{ Increased virus binding to $\alpha 2-6 \mathrm{SA}$} \\
\hline T156A & A & A & A & A & $\mathrm{T}$ & A & \\
\hline T188I & $\mathrm{T}$ & $\mathrm{I}$ & $\mathrm{T}$ & A & $\mathrm{T}$ & $\mathrm{T}$ & Increased pseudovirus binding to $\alpha 2-6 \mathrm{SA}$ \\
\hline A263T & $\mathrm{T}$ & $\mathrm{T}$ & $\mathrm{T}$ & $\mathrm{T}$ & $\mathrm{T}$ & $\mathrm{T}$ & The residue is related to virulence. \\
\hline $222-224$ & QGG & QRG & QRG & QRG & QRG & QSG & $\begin{array}{l}222-224 \mathrm{QS}(\mathrm{R}) \mathrm{G} \text { avian-like } \alpha 2-3 \\
\text { receptor binding preference }\end{array}$ \\
\hline Cleavage peptides & RERRRKR & REKRRKR & REKRRKR & RERRRKR & RERRRKR & RERRRKR & Highly pathogenic avian influenza \\
\hline \multicolumn{8}{|l|}{ NA (N6 no.) } \\
\hline E119D/V & $E$ & $E$ & $E$ & $E$ & $E$ & $E$ & \multirow{5}{*}{ Antiviral oseltamivir resistance } \\
\hline A247V & A & A & A & A & A & A & \\
\hline $\mathrm{H} 274 \mathrm{Y}$ & $\mathrm{H}$ & $\mathrm{H}$ & $\mathrm{H}$ & $\mathrm{H}$ & $\mathrm{H}$ & $\mathrm{H}$ & \\
\hline R293K & $\mathrm{R}$ & $\mathrm{R}$ & $\mathrm{R}$ & $\mathrm{R}$ & $\mathrm{R}$ & $\mathrm{R}$ & \\
\hline R372K & $\mathrm{R}$ & $\mathrm{R}$ & $\mathrm{R}$ & $\mathrm{R}$ & $\mathrm{R}$ & $\mathrm{R}$ & \\
\hline \multicolumn{8}{|l|}{ PB2 } \\
\hline K389R & $\mathrm{R}$ & $\mathrm{R}$ & $\mathrm{R}$ & $\mathrm{R}$ & $\mathrm{R}$ & $\mathrm{K}$ & \multirow{2}{*}{$\begin{array}{l}\text { Enhanced growth capacity in human and } \\
\text { mammalian cells }\end{array}$} \\
\hline V598T/I & $\mathrm{T}$ & $\mathrm{T}$ & $\mathrm{T}$ & $\mathrm{T}$ & $\mathrm{T}$ & V & \\
\hline \multicolumn{8}{|l|}{ PB1 } \\
\hline I368V & 1 & 1 & 1 & 1 & 1 & V & Transmissible among ferrets \\
\hline \multicolumn{8}{|l|}{ PA } \\
\hline N409S & $\mathrm{S}$ & $\mathrm{S}$ & $\mathrm{S}$ & S & $\mathrm{S}$ & $\mathrm{N}$ & $\begin{array}{l}\text { Increased virus replicative ability in } \\
\text { mammalian systems }\end{array}$ \\
\hline \multicolumn{8}{|l|}{ M1 } \\
\hline N30D & $\mathrm{D}$ & $\mathrm{D}$ & $\mathrm{D}$ & $\mathrm{D}$ & $\mathrm{D}$ & $\mathrm{D}$ & \multirow{3}{*}{ Increased virulence in mice } \\
\hline T139A & A & A & $\mathrm{T}$ & $\mathrm{T}$ & $\mathrm{T}$ & A & \\
\hline T215A & A & A & A & A & A & A & \\
\hline \multicolumn{8}{|l|}{ M2 } \\
\hline $\mathrm{D} 21 \mathrm{G}$ & G & $\mathrm{D}$ & $\mathrm{D}$ & $\mathrm{D}$ & $\mathrm{D}$ & G & \multirow{5}{*}{ Antiviral amantadine resistance } \\
\hline L26F/I & $L$ & $L$ & $L$ & $\mathrm{~L}$ & L & L & \\
\hline A30T & A & A & A & A & A & A & \\
\hline S31N & $\mathrm{N}$ & $\mathrm{S}$ & $\mathrm{S}$ & $\mathrm{S}$ & $\mathrm{S}$ & $\mathrm{N}$ & \\
\hline G34E & G & G & G & G & G & G & \\
\hline \multicolumn{8}{|l|}{ NS1 } \\
\hline P42S & $\mathrm{S}$ & $\mathrm{S}$ & $\mathrm{S}$ & S & $\mathrm{S}$ & $\mathrm{S}$ & \multirow{3}{*}{ Increased virulence in mice } \\
\hline 80-84Del & Yes & Yes & Yes & Yes & Yes & No & \\
\hline L98F & M & M & M & M & M & M & \\
\hline
\end{tabular}


From January to July 2021, 2 cases were reported in Guangxi zhuang autonomous region. Compared with 4 H5N6 infections reported from 2016 to 2019, and the number of infections cases was slightly higher than that in previous years. It is necessary to sequence and analyze the virus. The case infected with GX01 had obvious clinical symptoms and a history of exposure to dead poultry. Homology analysis showed that GX01 virus was a recombinant virus of $\mathrm{H} 5 \mathrm{~N} 6$ and $\mathrm{H} 9 \mathrm{~N} 2$, while GX11151 was a recombinant virus of $\mathrm{H} 5 \mathrm{~N} 8$, H5N6, and H9N2. Previous study showed H5N6 lineage has been co-circulating in different regions in China (10-11). The mutations in the important sites of proteins of avian influenza virus may change the adaptivity, virulence, tissue tropism, and infectivity. The cleavage between HA1 and HA2 proteins of HA gene of these two viruses were multiple continuous basic amino acids motif (RERRRKR), indicating that they possessed potentially high pathogenicity in chickens. The 222-224 receptor binding site of HA gene suggested that the viruses were avian-like receptors ( $\alpha 2,3$ SA). Studies have shown that the sensitivity of viruses carrying $\mathrm{H} 274 \mathrm{Y}$ mutation in NA protein to oseltamivir decreased 1,000 times. In addition, when the NA protein of the virus carries E119A/D/V, A247V, R293K, and R372K mutations, it will cause different degrees of resistance to oseltamivir and zanamivir (12-13). Fortunately, these mutations were not found in our virus. Therefore, using NA inhibitors to treat the 2 cases infected with avian influenza A (H5N6) was still a good choice.

The median age of the two cases was over 50 years old. Like other studies previously reported, the elderly people may be more vulnerable to avian influenza (3). One case was reported through ILI surveillance system (14), indicating that the ILI system was beneficial for the detection of avian influenza cases to a certain extent. However, this may be just the tip of the iceberg, and perhaps many mild cases have not been detected.

This study has certain limitations. Sampling of the environment exposed by the cases, and poultry around the living environment were missing, resulting in lacking of laboratory tests. One reason was that the period from onset to reporting was too long for sampling, in spite of dead poultry found in epidemiology survey, and another reason was that patient $\mathrm{B}$ had no clear history of exposure to poultry.

At present, coronavirus disease (COVID-19) has caused a worldwide pandemic (15), and over 200 million people have been infected. Meanwhile, the increasing trend of human infection with avian influenza virus has become an important public health issue that cannot be ignored, alerting us that COVID19 and avian influenza may be simultaneously prevalent in some regions.

Acknowledgments: Dr. Yu Lan and Dr. William J. Liu.

Funding: Supported by the Self-Funded Scientific Research Project of Guangxi Health and Family Planning Commission (Z2015457, Z2016433).

doi: $10.46234 / \mathrm{ccdcw} 2021.199$

\# Corresponding author: Jing Wang, wangjing0630@126.com.

\footnotetext{
${ }^{1}$ Guangxi Key Laboratory of Major Infectious Disease Prevention and Control and Biosafety Emergency Response, Guangxi Center for Disease Control and Prevention, Nanning, Guangxi Zhuang Autonomous Region, China; ${ }^{2}$ Guilin Center for Disease Control and Prevention, Guilin, Guangxi Zhuang Autonomous Region, China; ${ }^{3}$ Hechi Center for Disease Control and Prevention, Hechi, Guangxi Zhuang Autonomous Region, China.

\& Joint first authors.
}

Submitted: August 25, 2021; Accepted: September 02, 2021

\section{REFERENCES}

1. World Health Organization. Avian influenza weekly update number 804. https:/www.who.int/docs/default-source/wpro---documents/emer gency/surveillance/avian-influenza/ai_20210806.pdf?Status=Master \&sfvrsn=5f006f99_42. [2021-8-6].

2. Sun HL, Pu J, Wei YD, Sun YP, Hu J, Liu LT, et al. Highly pathogenic avian influenza $\mathrm{H} 5 \mathrm{~N} 6$ viruses exhibit enhanced affinity for human type sialic acid receptor and in-contact transmission in model ferrets. J Virol 2016;90(14):6235 - 43. http://dx.doi.org/10.1128/JVI.00127-16.

3. Wang XL, Jiang H, Wu P, Uyeki TM, Feng LZ, Lai SJ, et al. Epidemiology of avian influenza a H7N9 virus in human beings across five epidemics in mainland China, 2013-17: an epidemiological study of laboratory-confirmed case series. Lancet Infect Dis 2017;17(8):822 32. http://dx.doi.org/10.1016/S1473-3099(17)30323-7.

4. Wang J, Jiang LN, Ning CY, Yang YP, Chen M, Zhang C, et al. First outbreak of human infection with avian influenza $A(H 7 N 9)$ virus in Guangxi, China, 2016 to 2017. Chin Med J (Engl) 2019;132(16):1995 - 7. http://dx.doi.org/10.1097/CM9.0000000000000376.

5. Chutinimitkul S, van Riel D, Munster VJ, van den Brand JMA, Rimmelzwaan GF, Kuiken $\mathrm{T}$, et al. In vitro assessment of attachment pattern and replication efficiency of $\mathrm{H} 5 \mathrm{~N} 1$ influenza a viruses with altered receptor specificity. J Virol 2010;84(13):6825 - 33. http://dx. doi.org/10.1128/JVI.02737-09.

6. Su Y, Yang HY, Zhang BJ, Jia HL, Tien P. Analysis of a point mutation in $\mathrm{H} 5 \mathrm{~N} 1$ avian influenza virus hemagglutinin in relation to virus entry into live mammalian cells. Arch Virol 2008;153(12):2253 - 61. http:// dx.doi.org/10.1007/s00705-008-0255-y.

7. Yang ZY, Wei CJ, Kong WP, Wu L, Xu L, Smith DF, et al. Immunization by avian $\mathrm{H} 5$ influenza hemagglutinin mutants with altered receptor binding specificity. Science 2007;317(5839):825 - 8 . http://dx.doi.org/10.1126/science.1135165.

8. Wang WJ, Lu B, Zhou HL, Suguitan AL Jr, Cheng X, Subbarao K, et al. Glycosylation at $158 \mathrm{~N}$ of the hemagglutinin protein and receptor binding specificity synergistically affect the antigenicity and immunogenicity of a live attenuated H5N1 A/Vietnam/1203/2004 vaccine virus in ferrets. J Virol 2010;84(13):6570-7. http://dx. doi.org/10.1128/JVI.00221-10. 
9. Bi YH, Chen QJ, Wang QL, Chen JJ, Jin T, Wong G, et al. Genesis, evolution and prevalence of $\mathrm{H} 5 \mathrm{~N} 6$ avian influenza viruses in China. Cell Host Microbe 2016;20(6):810 - 21. http://dx.doi.org/10.1016/ j.chom.2016.10.022.

10. Bi YH, Mei K, Shi WF, Liu D, Yu XL, Gao ZM, et al. Two novel reassortants of avian influenza A (H5N6) virus in China. J Gen Virol 2015;96(Pt 5):975 - 81. http://dx.doi.org/10.1099/vir.0.000056.

11. Xiao CK, Xu JA, Lan Y, Huang ZP, Zhou LJ, Guo YX, et al. Five independent cases of human infection with avian influenza H5N6 Sichuan Province, China, 2021. China CDC wkly 2021;3(36):751 - 6. http://dx.doi.org/10.46234/ccdcw2021.187.

12. Liu WJ, Wu Y, Bi YH, Shi WF, Wang DY, Shi Y, et al. Emerging
HxNy influenza A viruses. Cold Spring Harb Perspect Med 2020;a038406. https://doi.org/10.1101/cshperspect.a038406

13. Fan SF, Deng GH, Song JS, Tian GB, Suo YB, Jiang YP, et al. Two amino acid residues in the matrix protein $\mathrm{M} 1$ contribute to the virulence difference of $\mathrm{H} 5 \mathrm{~N} 1$ avian influenza viruses in mice. Virology 2009;384(1):28 - 32. http://dx.doi.org/10.1016/j.virol.2008.11.044.

14. Ip DKM, Liao QH, Wu P, Gao ZC, Cao B, Feng LZ, et al. Detection of mild to moderate influenza $\mathrm{A} / \mathrm{H} 7 \mathrm{~N} 9$ infection by China's national sentinel surveillance system for influenza-like illness: case series. BMJ 2013;346:f3693. http://dx.doi.org/10.1136/bmj.f3693.

15. World Health Organization. WHO Coronavirus (COVID-19) Dashboard. https://covid19.who.int/. [2021-9-2]. 